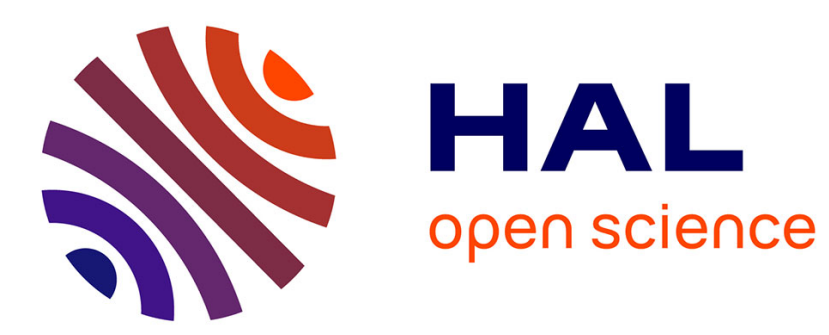

\title{
Visual agnosia and imagery after Lissauer
}

Paolo Bartolomeo

\section{To cite this version:}

Paolo Bartolomeo. Visual agnosia and imagery after Lissauer. Brain - A Journal of Neurology , 2021, 10.1093/brain/awab159 . hal-03241920

\section{HAL Id: hal-03241920 \\ https: / hal.sorbonne-universite.fr/hal-03241920}

Submitted on 29 May 2021

HAL is a multi-disciplinary open access archive for the deposit and dissemination of scientific research documents, whether they are published or not. The documents may come from teaching and research institutions in France or abroad, or from public or private research centers.
L'archive ouverte pluridisciplinaire HAL, est destinée au dépôt et à la diffusion de documents scientifiques de niveau recherche, publiés ou non, émanant des établissements d'enseignement et de recherche français ou étrangers, des laboratoires publics ou privés. 


\section{Visual agnosia and imagery after Lissauer}

Paolo Bartolomeo ${ }^{1}$

\section{Author affiliations:}

1 Sorbonne Université, Institut du Cerveau - Paris Brain Institute - ICM, Inserm, CNRS, APHP, Hôpital de la Pitié-Salpêtrière, F-75013 Paris, France

Correspondence to: Paolo Bartolomeo

INSTITUT DU CERVEAU

HOPITAL PITIE-SALPETRIERE

47 BOULEVARD DE L'HOPITAL

CS 21414

75646 PARIS CEDEX 13

E-mail paolo.bartolomeo@icm-institute.org

Running title: Moving Lissauer forward

Keywords: Visual perception; visual mental imagery; white matter disconnection; ventral temporal cortex 
The year 2021 marks the 130th anniversary of the untimely death of Heinrich Lissauer (18611891). In his thirty years of life, Lissauer managed to put together an impressive number of contributions to neurology and neuroanatomy. Most influential is his famous distinction between apperceptive and associative forms of visual agnosia. It is perhaps less well-known that in the same article, Lissauer outlined a model of possible dissociations between visual perception and visual mental imagery. Drawing on Hermann Munk's animal experiments, Lissauer proposed that complete destruction of occipital visual cortex would provoke both perception and imagery deficits, whereas its deafferentation resulting from subcortical white matter damage would only affect visual perception, and leave visual memories unimpaired. This proposal resonates with the present debate on the neural bases of visual mental imagery.

In 1890, Heinrich Lissauer, then an assistant in Carl Wernicke's Breslau clinic, provided a detailed description of a patient with "mind blindness" (Seelenblindheit) (English translation in Ref. 1). Gottlieb L., an 80-year-old salesman, had suddenly become "quite incapable of visually recognising the most common objects, although he could recognise everything by touch or hearing" (Ref. 1, p. 160). The following year, Sigmund Freud would introduce the modern label "agnosia" for these disorders of recognition. Lissauer's patient had a dense right-sided homonymous hemianopia with macular sparing, and reasonably preserved visual acuity in his intact field. Reading was impossible, but he could write fluently and without errors.

On the basis of extensive behavioural testing, Lissauer concluded that his patient "perceived many things without comprehending them" (p. 160). In Lissauer's theoretical framework, the patient had normal conscious awareness of sensory impressions (“apperception"), but could not associate the content of apperception with stored knowledge. Lissauer thus outlined here the famous dichotomy between apperceptive and associative 
agnosias (although he did not see this distinction as an absolute one, and did not expect to find pure examples of either form of agnosia).

Can patients with visual agnosia use their "mind's eye" to conjure up mental images of the objects they cannot recognise? Visual mental imagery designates our ability to mentally visualize objects that are not in our direct line of sight (Fig. 1). For example, most of us can state from memory whether the (typical) red of cherries is darker or lighter than the red of strawberries, or whether or not Monna Lisa is staring at us from Leonardo da Vinci's painting. In visual mental imagery, information from semantic memory (such as the typical appearance of cherries and strawberries) is modeled to simulate a specific perceptual problem (compare the hues). Some patients with visual agnosia lose this ability in parallel with their perceptual impairment; others, however, show dissociations of performance, with impaired perception but preserved mental imagery ${ }^{2}$. Concerning Gottlieb L., Lissauer noted that "[f]urther discussion is required to decide whether the patient really had a clear visual memory or visual imagery or whether his perception of common objects was related to concise mental pictures. As is well known, visual imagery is a variable characteristic of which few really definitive personal reports, such as Charcot's famous patient, are available. Only gross deficits in visual imagery lend themselves to clinical investigation. Although confirmation of such deficits would be of great theoretical importance, in practice they are very difficult to study. A patient can be asked to describe from memory the shape and the colour of a given object, or of an animal or a plant. In many instances our patient was able to give satisfactory descriptions. For example, he described both in words and by indicating the relative sizes what an eel looked like, a plaice, a swan, an apple, a pear, a plum, and a cherry. There was therefore no good evidence of a deficit in his ability to visualise mentally" (p. 166).

Concluding his case report, Lissauer discusses his patient's pattern of performance in relation to contemporary models of visual processing. He states that "it is accepted that visual 
agnosia is caused by moderately extensive damage to the occipital cortex. It is a fact that during the process of recognising a sensory impression that part of the cortex that has to effect recognition is activated first. There then follow a series of associative processes which elicit the various determining memory images relating to the object concerned. To activate these images it is necessary for the excitation to spread from the perceiving part of the cortex to the whole of the cortex in order to elicit throughout a specific and finely tuned reaction. This is the process which in our case must have been mediated by the transcortical tracts of the visual cortex. A blockage of transmission along these tracts [...] would prevent a linkage between perception and those associations which are normally necessary for the process of recognition and this would result in visual agnosia" (p. 186).

Lissauer's discussion here is grounded on the theoretical models and empirical evidence of his time. His boss Wernicke maintained that modality-specific cortical areas, such as the visual cortex, contain 'memory images' related to sensory experiences. On the other hand, Hermann Munk (1839-1912) had coined the term 'mind blindness' (Seeleblindheit) to describe the deficits of visual recognition that occurred in dogs by partially damaging the posterior part of their occipital cortex ${ }^{3}$. Munk considered that the operated dogs had forgotten the meaning of previously familiar visual objects. However, they remained able to avoid obstacles and navigate, hence the term mind blindness. Larger occipital lesions provoked instead total (cortical) blindness.

Lissauer makes then an important distinction between cortical and subcortical (white matter) damage. "We have so far considered only one visual field as if the hemianopic field had been totally eliminated. This elimination would be complete if the existing loss of the right visual field was the result of the destruction of the visual field itself, i.e. if this was a case of visual agnosia and cortical hemianopia. In that case there would be no replacement in the hemianopic hemisphere for the loss of memory images reported in other cases of visual 
agnosia. It is different, however, if the hemianopia is of subcortical origin. In that case memory images of that hemisphere would be available to the conscious mind, unimpaired, despite an existing visual agnosia for all visual perceptions" (p. 187, emphasis added).

In other words, direct damage to the visual cortex would also eliminate visual mental images. However, if the visual cortex is only deafferented by white matter damage, then perception would be affected, but the deafferented cortex could still sustain visual mental imagery. Lissauer believed that this last case applied to Gottlieb L.'s pattern of performance. Importantly, here Lissauer offers a principled explanation for associations and dissociations of disorders of perception (agnosia) and of visual mental imagery. Specifically, Lissauer's words imply that visual mental imagery results from top-down activation of the primary visual cortex.

These considerations resonate with the current debate on the neural bases of visual mental imagery. The currently dominant neural model of visual mental imagery stresses the importance of early visual cortex for this ability ${ }^{4}$, in line with Lissauer's proposal. Contrary to this view, however, we know today that brain-damaged patients with damage restricted to the occipital cortex typically have perfectly normal visual mental imagery abilities and phenomenology ${ }^{2}$. On the other hand, consistent with Lissauer's ideas, white matter disconnections can determine dissociations between perception and imagery deficits. For example, Madame D., a patient with bilateral, predominantly white matter damage at the borders between occipital and temporal cortex ${ }^{5}$, had severe deficits of visual recognition for forms, colours, letters and faces. Nevertheless, she could conjure up high-definition mental images of all these items ${ }^{6}$. White matter damage severely perturbed her visual perceptual processing, while completely sparing her visual mental imagery, possibly sustained by topdown activity in the intact temporal cortex. In sharp contrast, patients with more anterior lesions in the temporal lobe, especially in the left hemisphere ${ }^{7}$, may show deficits of visual mental imagery (today often labelled as acquired aphantasia ${ }^{8}$ ). Consistent with this abundant 
neuropsychological evidence, a recent meta-analysis of functional MRI studies in normal participants ${ }^{9}$ demonstrated the engagement of the left ventral temporal cortex in visual mental imagery; Bayesian analysis excluded a role for occipital cortex.

Lissauer's model of visual cognition was based on Munk's early hypothesis that all visual processing occurred in the occipital cortex. It can benefit today from a more refined knowledge on the large-scale circuits subserving visual identification, spanning from the occipital cortex to the temporal pole, and receiving important contributions from more dorsal, fronto-parietal networks ${ }^{10}$. More articulated models of visual mental imagery are now available, based on large-scale circuits including anterior, ventral and mesial temporal cortex, as well as fronto-parietal networks of attention and working memory ${ }^{9}$. The theoretical landscape emerging from these considerations is certainly reminiscent of Lissauer's distinction between cortical and subcortical lesions in the determinism of perceptual and imagery deficits. However, recent evidence suggests that the crucial cortical region here is not the primary visual cortex, but high-level visual areas in the ventral temporal cortex. Thus, Lissauer's 1890 model of visual knowledge still makes a lot of sense today, provided that its neural nodes are pushed forward along the occipito-temporal visual pathway.

\section{Funding}

The work of the author is supported by the Agence Nationale de la Recherche through ANR16-CE37-0005 and ANR-10-IAIHU-06, and by the Fondation pour la Recherche sur les AVC through FR-AVC-017.

\section{Competing interests}

The author reports no competing interests. 


\section{References}

1. Lissauer H, Jackson M. A case of visual agnosia with a contribution to theory. Cognitive Neuropsychology. 1988;5(2):157-192. doi:10.1080/02643298808252932

2. Bartolomeo P, Hajhajate D, Liu J, Spagna A. Assessing the causal role of early visual areas in visual mental imagery. Nat Rev Neurosci. Sep 2020;21(9):517. doi:10.1038/s41583-020-0348-5

3. Finger S. Origins of neuroscience: a history of explorations into brain function. Oxford University Press; 1994:1 vol. (XVIII-462 p.).

4. Pearson J. The human imagination: the cognitive neuroscience of visual mental imagery. Nat Rev Neurosci. 2019;20(10):624-634. doi:10.1038/s41583-019-0202-9 PMID 31384033

5. Bartolomeo P, Bachoud-Levi AC, Thiebaut de Schotten M. The anatomy of cerebral achromatopsia: a reappraisal and comparison of two case reports. Cortex. Jul 2014;56:138-44. doi:10.1016/j.cortex.2013.01.013

6. Bartolomeo P, Bachoud-Lévi AC, de Gelder B, et al. Multiple-domain dissociation between impaired visual perception and preserved mental imagery in a patient with bilateral extrastriate lesions. Neuropsychologia. 1998;36(3):239-249.

7. Bartolomeo P, Bachoud-Lévi AC, Chokron S, Degos JD. Visually- and motor-based knowledge of letters: evidence from a pure alexic patient. Neuropsychologia. 2002;40(8):1363-1371.

8. Zeman A. Aphantasia. In: Abraham A, ed. The Cambridge Handbook of the Imagination. Cambridge University Press; 2020.

9. Spagna A, Hajhajate D, Liu J, Bartolomeo P. Visual mental imagery engages the left fusiform gyrus, but not the early visual cortex: A meta-analysis of neuroimaging evidence. Neurosci Biobehav Rev. Mar 2021;122:201-217. doi:10.1016/j.neubiorev.2020.12.029

10. Bartolomeo P, Vuilleumier P, Behrmann M. The whole is greater than the sum of the parts: Distributed circuits in visual cognition. Cortex. Nov 2015;72:1-4. doi:10.1016/j.cortex.2015.09.001 


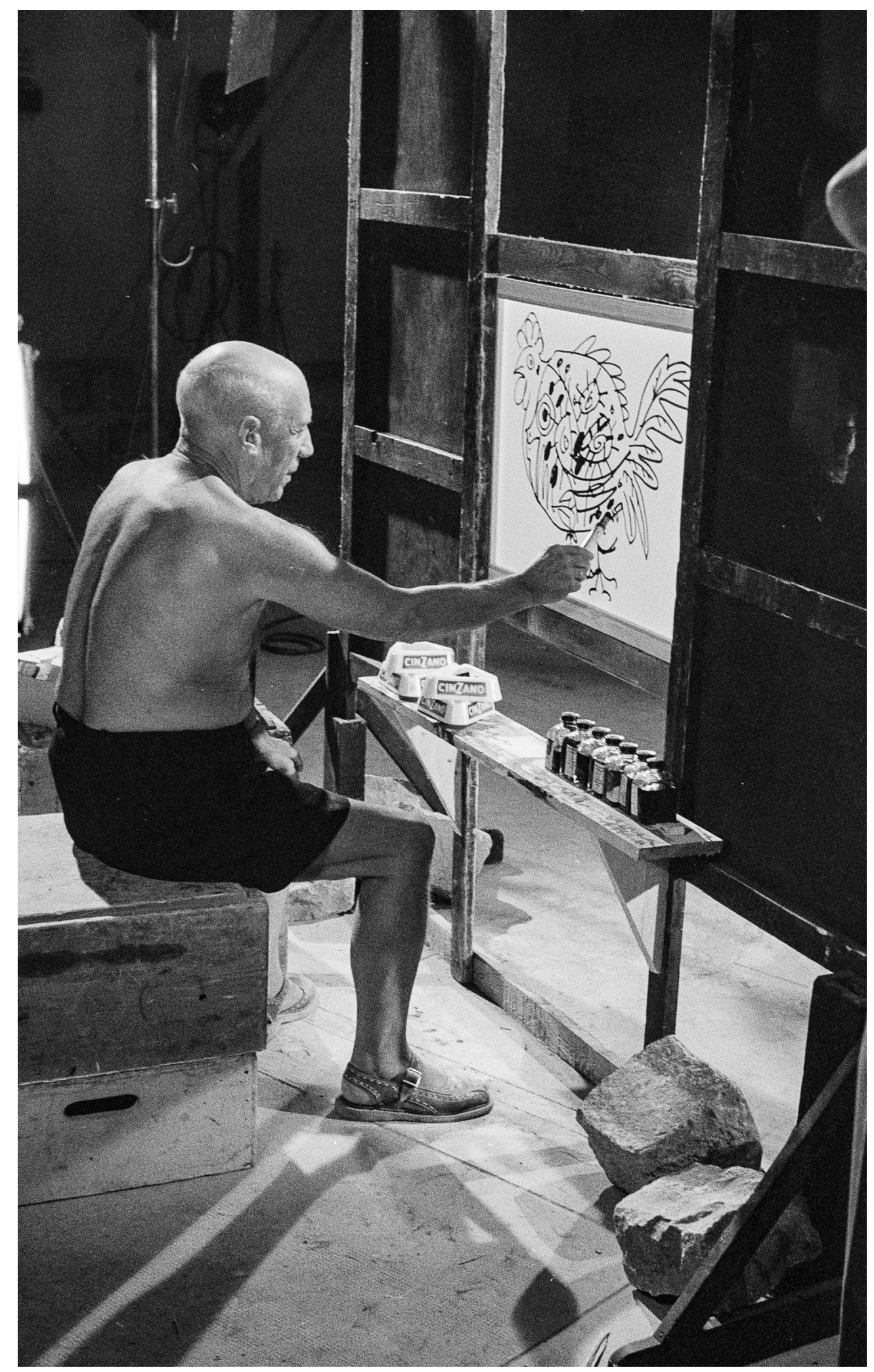

Figure 1 Pablo Picasso using his remarkably vivid visual mental imagery to paint without any external model. Photograph taken during the shooting of "Le Mystère Picasso" (1955), by Henri-Georges Clouzot. Photo Edward Quinn, (C) edwardquinn.com 